\title{
Climatic Variability and Performance of Small Scale Industries in Ado-Ekiti, Ekiti State, Nigeria
}

\author{
Aladelokun, A.O (Ph.D) ${ }^{1^{*}}$, Ayodele, M.B ${ }^{1}$, Oluwatuyi, O.V ${ }^{2}$ \\ ${ }^{I}$ Department of Geography College of Education Ikere-Ekiti, Ekiti State. \\ ${ }^{2}$ Olive Dataminds, Ado-Ekiti, Ekiti State.
}

*Corresponding Author: Aladelokun, A.O (Ph.D), Department of Geography College of Education Ikere-Ekiti, Ekiti State.

\begin{abstract}
Climatic variability describes the short-term changes in climate that takes place over months, seasons and years in a particular environment. It looks at changes that occur in the earth's climate within smaller timeframes usually between a month and 5 years. The earth's climatic system exists in such a way that it supports human survival and development. Industrial development, which is a key factor to economic development functions at the mercy of climatic condition. In Ado Ekiti, small scale industries contribute immensely to the state's economy through the creation of jobs and revenue generation. This study assesses climatic variability in Ado-Ekiti vis-a-vis its relationship with performance of small scale industries in AdoEkiti. Climate data (temperature and rainfall) of Ado Ekiti was obtained from NIMET. Data on the influence of climatic variability on performance of small scale industries was collected from 50 small scale industries in Ado-Ekiti with at least 10 years of establishment. A significant variation was experienced in the annual mean rainfall received in Ado-Ekiti between 1996 and 2003 and also between 2011 and 2017 while only few variations were experienced on the mean temperature received with few notable fluctuations in 1998, 1999, 2002, 2010, 2014 and 2018. A significant relationship was also established between rainfall variability and performance of small scale industries while temperature variability has no significant relationship with performance of small scale industries in Ado-Ekiti. The variations in the amount of rainfall received significantly influence the availability of raw materials and level of patronage. There is therefore need to properly enlighten entrepreneurs on how to develop adapting strategies in the face of fluctuating climatic conditions.
\end{abstract}

Keywords: Climatic Variability, Annual Mean Temperature, Annual Mean Rainfall, Small Scale Industries

\section{INTRODUCTION}

The earth's system exists in such a way that it was made to support human survival; one of the most essential aspects of it is the earth's climate. Climate is distinguished from weather, which is the specific behaviour of the climate at a particular time. Climate is often referred to as long term weather condition of a geographical coverage. It is rather what we expect, while weather is what we get. Earth's climate is primarily characterized by elements such as nitrogen, oxygen, argon and small amounts of other gases. The aforementioned gases; although in abundance, are inert and does not play major role in our day to day weather (Ayoade, 2004). However, in the troposphere, where the weather forms, there are variable gases such as water vapour, carbon-dioxide, methane, dust, ozone etc., which predicts our weather condition and on the long run our climate.

In developing an economy, certain factors immediately come to mind with little emphasis on the most germane one; the climate system. Overtime, this misplacement of priority has resulted to consequential effects, one of which is climate change. Climate change although synonymous to climatic variability means the change in the longer term pattern of behaviour of the atmosphere over millennia or, more recently, as a result of natural processes or human activity (Newsham, 2018). Climatic variability on the other hand, looks at changes that occur in the earth's climate within smaller timeframe seasons usually between a month and 5 years. In other words, climatic variability describes short-term changes in climate that takes place over months, seasons and years in a particular environment. Climatic variability can also be referred to as change in mean amount of climatic variables often experienced in place over a given period of time. These variables include the temperature, humidity, precipitation and wind (Ezegwu, 2014). 
The climate of a particular region has regular seasonal and diurnal variations. Natural events and human activities are believed to be contributing to an increase in the average global and local climatic conditions. Baede (2010) noted that climate variations and change, caused by external forces, may be partly predictable. Because, human activities such as emission of greenhouse gases or land-use change do result in external forcing.

Small scale industries have often been linked by researchers to economic development while climate can have its impact. The definition of small scale industries tend to differ among countries and individuals. Thus, there is no universally accepted definition of small-scale industry. According to Banik (2018), small scale industries (SSI) simply refer to those small entrepreneurs who are engaged in production, manufacturing or service at a micro scale. The Central Bank's Credit Guidelines to Scale Enterprises in Nigeria asserted that SSI are establishments whose annual turnover (sale figure) does not exceed $\$ 500,000$ with fewer than 50 full-time workers. Small scale industries are expected to play pivotal role in Nigeria's industrial development. This is based on the fact that they serve as grassroots industries and have constant supply of potential entrepreneurs who are ready to take a chance on the exploration of new ideas or favourable market opportunity. They also create more jobs per unit of invested capital and per unit energy consumed (CBN, 1988). Altenburg and Eckhardt (2006) also emphasize that small scale is the lifeblood of the economic growth of a country in which their performance is closely associated with the performance of the nation.

In Nigeria, the importance of small scale enterprise cannot be over-emphasized, Ado-Ekiti not an exception. As the capital city of Ekiti State, most of the industries there are at low scale. They complement government organizations through job creation and revenue generation. Industries are planned and set-up to work in cognizance with the climate of the environment in which they exist. This is usually based on the prior knowledge of the climate they have been experiencing. A change in this will likely hinder their plans and activities. Researchers have linked several factors to organizational growth and unsatisfactory level of performance with little or no work done to establish the relationship that exists between climatic variability and performance of SSI in Ado-Ekiti. This paper therefore sets to fill such gap.

\section{OBJECTIVES OF THE STUDY}

The objective of this study was to investigate climatic variability and performance of small scale industries in Ado-Ekiti, Ekiti State. Specifically the study would;

1. investigate the trend of climatic variability in Ado-Ekiti

2. examine the influence of climatic variability on the performance of small and medium scale enterprise in Ado-Ekiti

\subsection{Hypotheses}

The following hypotheses were formulated for the study

1. There is no significant relationship between temperature variability and performance of small scale industries in Ado-Ekiti

2. There is no significant relationship between rainfall variability and performance of small scale industries in Ado-Ekiti.

\subsection{Scope of the Study}

The study covered the range of 23 years from 1996 to 2018. The idea behind the data used was based on two major facts which are, the year the state was created and availability of climate data. Annual mean rainfall and annual temperature are the major climatic variables employed.

\subsection{Area of the Study}

Ado-Ekiti; the capital city of Ekiti State which was declared a state on 1st of October 1996 by the then military government under General Sani Abacha is located within the North Western part of the Benin-Owena River Basin development Area. The city lies between Latitude $7^{\circ} 34^{1}$ and $7^{\circ} 44^{1}$ North of the Equator and Longitude $5^{\circ} 11^{1}$ and $5^{\circ} 18^{1}$ East of the Greenwich Meridian. It has a number of Satellite towns around it. To the North is Iworoko, about 16 kilometers away from the city; to the east are Are and Afao, about 16 kilometers; to the West are Iyin and Igede, about $20 \mathrm{~km}$ and to the South is 
Ikere, about $18 \mathrm{~km}$. Ado-Ekiti enjoys the privilege of been a nodal town and located at the centre of the state; hence roads that leads to other parts of the state converge in the city. Inhabited majorly by the Yoruba of Southwestern Nigeria, it experiences tropical wet and dry climate based on the Koppen climate classification. The wet season lasts from April to October with a break in August and dry season lasts from November to February. Howbeit, the temperature of the area is almost uniform throughout the year with very little deviation from the mean annual temperature of $27^{\circ} \mathrm{C}$, February and March are the hottest with an average temperature of $28^{\circ} \mathrm{C}$ and $29^{\circ} \mathrm{C}$ respectively, while June with mean temperature of $25^{\circ} \mathrm{C}$ is the coolest.

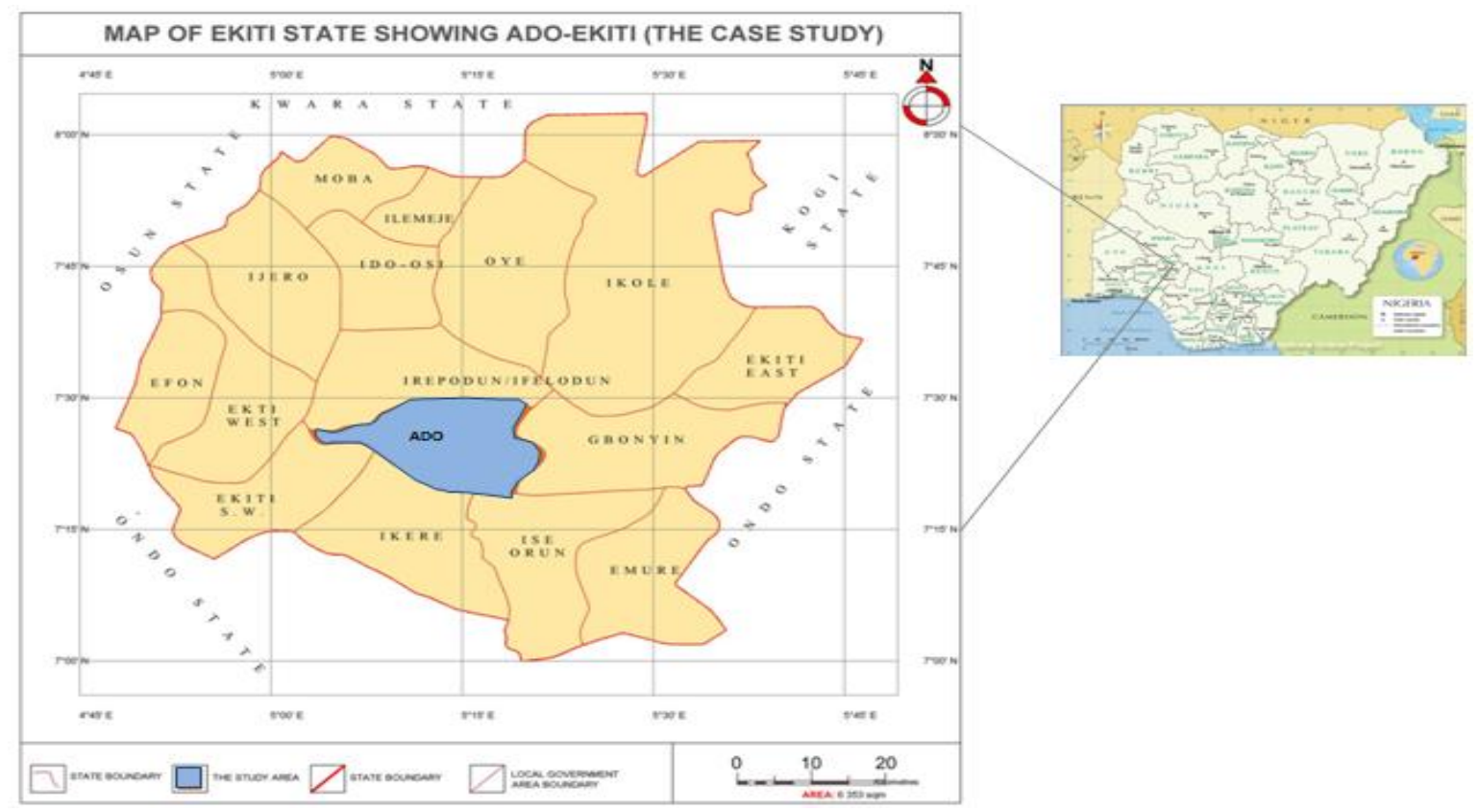

Figure1. Map of Ado-Ekiti in Ekiti State, Nigeria

\section{Methodology}

Data used for the study were obtained from both primary and secondary sources. Data on climatic variables (rainfall and mean temperature) spanning from 1996 to 2018 was collected at the Nigerian Meteorological Agency (NIMET) in Oshodi, Lagos. Data on development of small scale industries was obtained from the ministry of investments, trade and industry while data on performance was obtained from some selected small scale industries in Ado-Ekiti. A total of 50 small scale industries that have spent at least 10 years were identified and purposively selected to collect data on their performance over time. Data collected was analyzed using both descriptive statistics and inferential statistics. Simple percentage was used to describe the data obtained while Pearson Product Moment Correlation Coefficient (PPMCC) was used to examine the relationship between the variables. Linear trend analysis was used to ascertain the variability of the climatic variables over time.

\subsection{Data Presentation and Analysis}

The below figure 2 and 3 revealed the trend of climatic variability in Ado-Ekiti

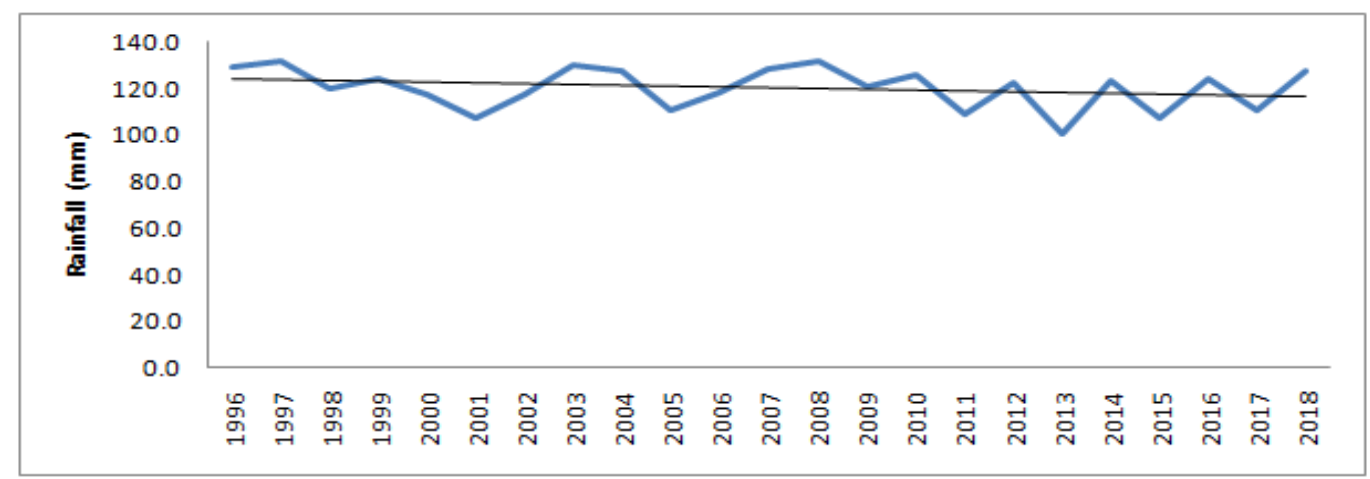

$\mathbf{N}=23$ years

Mean $=\mathbf{1 2 0 . 2 5}$ SD $=\mathbf{8 . 9 4 3}$

Figure2. Trend of annual mean rainfall of Ado-Ekiti (1996-2018) 
The average annual mean rainfall experienced in Ado-Ekiti between1996 - 2018 is $120.25 \mathrm{~mm}$ with a standard deviation of 8.943. The amount of rainfall received annually is considered to be normal if it falls between 111.3 and 129.2. However, a significant variation in the amount of rainfall received was experienced between 1996 and 2003 and also between 2011 and 2017.

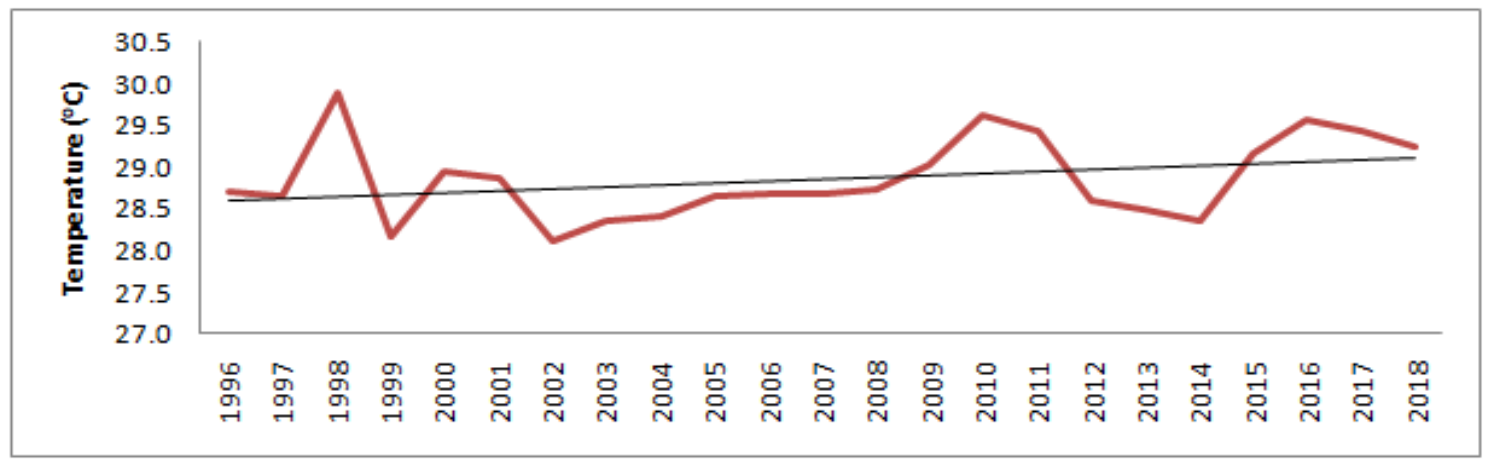

Figure3. Trend of annual mean temperature of Ado-Ekiti (1996-2018)

$$
\mathbf{N}=\mathbf{2 3} \text { years } \quad \text { Mean }=\mathbf{2 8 . 8 7} \quad \mathrm{SD}=\mathbf{0 . 4 8 9}
$$

The average annual mean temperature experienced in Ado-Ekiti between $1996-2018$ is $28.87^{\circ} \mathrm{C}$ with a standard deviation of 0.489 . The amount of temperature received annually is considered to be within acceptable limits if it falls between $28.4^{\circ} \mathrm{C}$ and $29.4^{\circ} \mathrm{C}$. However, a significantly high variation was experienced in the mean annual temperature in 1998, 2010 and 2016 while the mean annual temperature in 1999, 2002 and 2014 were significantly low.

\subsection{Test of Hypotheses}

$\mathbf{H O}_{1}$ : There is no significant relationship between temperature variability and performance of small scale industries in Ado-Ekiti

Table1. PPMCC showing the relationship between temperature variability and performance of Small Scale Industries in Ado-Ekiti

\begin{tabular}{|c|c|c|c|c|c|}
\hline Variables & N & Mean & SD & r. & sig. \\
\hline Temperature & 20 & 28.83 & .465 & \multirow{2}{*}{.174} & \multirow{2}{*}{.463} \\
\hline Performance of Small Scale Industries & 50 & 13.68 & 1.253 & & \\
\hline
\end{tabular}

$\mathrm{p}<0.05$

\section{Source: Survey, 2020}

Result presented in Table 2 on the relationship between temperature and performance of small scale industries showed that $\mathrm{r}(2050)=.174$ at $\mathrm{p}>0.05$. Hence the hypothesis is accepted which implies that there is no significant relationship between temperature variability and performance of small scale industries in Ado-Ekiti.

$\mathbf{H O}_{2}$ : There is no significant relationship between rainfall variability and performance of small scale industries in Ado-Ekiti.

Table2. PPMCC showing the relationship between rainfall variability and performance of Small Scale Industries in Ado-Ekiti

\begin{tabular}{|c|c|c|c|c|c|}
\hline Variables & N & Mean & SD & r. & sig. \\
\hline Rainfall & 20 & 119.21 & 8.949 & \multirow{2}{*}{-.39} & \multirow{2}{*}{.020} \\
\hline Performance of Small Scale Industries & 50 & 13.68 & 1.253 & & \\
\hline
\end{tabular}

$\mathrm{p}<0.05$

Source: Survey, 2020

Result presented in Table 2 on the relationship between rainfall and performance of small scale industries showed that $\mathrm{r}(2050)=-.39$ at $\mathrm{p}<0.05$. Hence the hypothesis is rejected which implies that there is a significant relationship between rainfall variability and performance of small scale industries in Ado-Ekiti. In addition, it was revealed that a negative relationship exists between rainfall and performance of small scale industries. In essence, high variability in the amount of rainfall received leads to low performance of small scale industries vice versa. 
Table3. Influence of Climatic variability on Performance of Small Scale Industries

\begin{tabular}{|l|l|l|l|l|}
\hline Does climatic variability influence the following: & Temperature Variability & \multicolumn{2}{l|}{ Rainfall Variability } \\
\cline { 2 - 5 } & Yes (\%) & No (\%) & Yes (\%) & No (\%) \\
\hline Availability of Raw Materials & 22 & 78 & 80 & 20 \\
\hline Level of Patronage & 18 & 89 & 32 & 68 \\
\hline Productivity/Services & 6 & 94 & 16 & 84 \\
\hline Profit & 12 & 88 & 26 & 74 \\
\hline
\end{tabular}

Source: Survey, 2020

It was revealed in Table 3 that $22 \%$ of the respondents were of the opinion that temperature variability influences the availability of raw materials, $18 \%$ of the respondents noted that it does influence level of patronage, $6 \%$ noted that it influences productivity/services while $12 \%$ were of the opinion that it affects their profit level. On the other hand, it was revealed that $80 \%$ of the respondents agreed that rainfall variability affects the availability of raw materials, $32 \%$ noted that it affects level of patronage, $16 \%$ agreed that it does influence productivity/services while $26 \%$ noted that rainfall variability affects their profit level.

\section{CONCLUSION AND RECOMMENDATIONS}

Climatic variability considers changes that occur in climate of an environment within a small timeframe. This study examined the variability in the annual mean temperature and amount of rainfall in Ado-Ekiti vis-a-vis its relationship with performance of small scale enterprise. A significant variability in the amount of rainfall received was experienced between 1996 and 2003 and also between 2011 and 2017. During these periods, the amount of rainfall received in 1996, 1997, 2003, and 2008 were high while low amount of rainfall were received in 2001, 2005, 2011, 2013, 2015 and 2017. Results on the variation in the annual mean temperature in Ado-Ekiti between 1996 and 2018 revealed that the variations in the amount of temperature was low with only few variations in 1998, 1999, 2002, 2010, 2014 and 2016.

A significant negative relationship was established between rainfall variability and performance of small scale industries in Ado-Ekiti while there is no significant relationship between temperature and performance of small scale industries in Ado-Ekiti. In essence, changes in the patterns of rainfall experienced in Ado-Ekiti affects the performance of small scale industries while changes in temperature do not. Furthermore, it was revealed that variability in the amount of rainfall received affects the performance of small scale industries in the availability of raw materials and level of patronage. This is due to the fact that most of small scale industries in Ado-Ekiti depend largely on agricultural products which are directly influenced by fluctuations in climatic variables.

To this end, entrepreneurs at micro and small scale level need to be properly enlightened on how to develop adapting/coping strategies in the face of changing climatic condition. In addition, microcredit loans should be made available to small scale industries at a very low interest rate to build strong resilience against climate change and to cushion the possible impacts of climatic variability on organizational performance.

\section{REFERENCES}

[1] Altenburg, T., \& Eckhardt, U. (2006). Productivity enhancement and equitable development: Challenges for SME development. Retrieved from http://www.unido.org/fileadmin/import/59567_06COMPID_059 1423_Ebook.pdf.

[2] Ayoade, J. O. (2004). Introduction to climatology for the tropics. Ibadan: Spectrum Books Limited.

[3] Baede, A.P. (2010). The climate system: An overview. Cambridge University Press, Cambridge, United Kingdom and New York, NY, USA, 87-98.

[4] Banik, S. (2018). Small scale industries in India: Opportunities and challenges. International Journal of Creative Research Thoughts, 6(1), 336-341.

[5] Central Bank of Nigeria (1988). Small scale industries in Nigeria: Concepts, Appraisal of some government policies and suggested solutions to identified problems. Surveys of Business Establishment, 25.

[6] Eniola, A.B., Entebang, H., Sakariyau, O. (2015). Small and medium scale business performance in Nigeria: Challenges faced from an intellectual capital perspective. International Journal of Research Studies in Management, 1-13. 
[7] Ezegwu, C. (2014). Climate change in Nigeria: The Impact and adaptation strategies. Retrieved from http://dx.doi.org/10.2139/ssrn.2543940 1-14.

[8] Newsham, A., Daley, B., Poulton, C., Pradhan, S., Guendel, S., \& Smith, L (2018). Climate change and development. Centre for development, environment and policy. University of London.

Citation: Aladelokun, A.O (Ph.D), et.al. "Climatic Variability and Performance of Small Scale Industries in Ado-Ekiti, Ekiti State, Nigeria” International Journal of Research in Geography. vol 6, no. 2, 2020, pp. 01-06 doi: http://dx.doi.org/10.20431/2454-8685.0602001.

Copyright: (C) 2020 Authors. This is an open-access article distributed under the terms of the Creative Commons Attribution License, which permits unrestricted use, distribution, and reproduction in any medium, provided the original author and source are credited. 